\title{
A comperative study of cyclic fatique resistance of two rotary systems files in artificial canals
}

\author{
Emre Ovsay
}

Lecturer, Dept. of Endodontics, Yeditepe Unıversıtesı D1s Hekımlığı FakultesıBagdat caddesi, Ciftehavuzlar, Istanbul, Turkey

*Corresponding Author: Emre Ovsay

Email: emreovsay@yahoo.com

\begin{abstract}
To aim of this study is to evaluate the cyclic fatique resistance of two different Ni-Ti rotary files Protaper Next and Fantadental V-Taper Gold at angle of 60 degrees in a metal block. This study was done with 7 files in each group including Protaper Next \#25(Group 1) and Fantadental V-Taper Gold files\#25(Group 2). The files were tested in artificial $60^{\circ}$ curved canal on computer (CNC) machined metal block at a constant body temperature at 36.5 degrees. Each file rotated in a 360 motion with $350 \mathrm{rpm}$ speed and $2.5 \mathrm{Ncm}$ torque (Xsmart plus, Dentsply) until files were fractured. The time elapsed during rotation were recorded and the length of fractured part of the instruments measured for each file. Mann-Whitney U test was used to compare two independent groups. Kruskal-Wallis test was conducted to compare time and length among groups. The time periods and the length of the fractured parts of the instruments in each group: Group1 Protaper Next \#25 10:05 $\pm 0,76 \mathrm{sec}(\mathrm{n}=7)$; Group2 Fanta V-Taper Gold\#25: 24:02 $\pm 0: 36 \mathrm{sec} /(\mathrm{n}=7)$. There was significant difference observed between cyclic fatigue of Group1 Protaper Next Files\#25 and Group2 Fanta V-Taper Gold Files\#25. No significant differences between groups were apparent regarding length of the fractured part.
\end{abstract}

Keywords: Cyclic Fatique, Protaper Next,V-Taper Gold.

\section{Introduction}

NiTi rotary instruments are popular among clinicians because of their high flexibility and elasticity when compared with stainless steel files. Nickel-titanium (NiTi) file fracture during root canal preparation is one of the most frequently seen complications. ${ }^{1,2}$ Removing the fractured segment of the file, which is inside the root canal, is usually a difficult process, and the amount of residual dentin tissue significantly decreases while taking the instrument outside the canal.As a result, the prognosis of endodontic treatment might be negatively affected. ${ }^{3}$ Cyclic fatigue occurs when all parts of NiTi file rotates continuously in the curved root canal. ${ }^{4}$ At that point, flexion and tension cycles occur until file is broken. All Studies showed that $70 \%$ of file fractures in curved root canals were caused by cyclic fatigue during shaping procedures. ${ }^{5}$ To avoid this unwanted situation, many investigations and renovations were done on metallurgical, chemical and mechanical properties of NiTi alloys to make files resistant to fracture. ${ }^{6}$

Protaper Next (Dentsply) and V-Taper Gold (Fanta Dental) are a new generation file systems that have recently been introduced and used in the market. Both file systems have $360^{\circ}$ motion. Both files have an S-shaped crosssection, two cutting edges and a non-cutting tip.According to manufactor's instructions V-Taper Gold has a special wiring technology that has more resistant to fracture.

\section{Materials and Methods}

A total of 14 Protaper Next and V-Taper Gold instruments size 25 used during root canal were tested. Each group tested in simulated canal with $60^{\circ}$ angle of curvature and a 3 $\mathrm{mm}$ radius at a constant speed of $350 \mathrm{rpm}$ and $2.5 \mathrm{~nm}$ torque until they were fractured.

The files were tested in a special apparatus at a constant temperature of $36.5^{\circ}$ which is equal to the temperature of normal body temperature. The files were exposed to cyclic fatigue test using a stainless steel device produced for and already used in previous studies. The specialized stainless steel block enabled the files to rotate freely within an artificial canal. The plastic top face cover over the apparatus allowed the visuality of the files rotating inside the canal and the removal of broken files during instrumentation. To reduce friction as the metal instrument contacted the metal canal walls, synthetic oil (Wd no:40; USA) was used. The time of fracture for each file was calculated and the data was compared using Mann-Whitney $U$ test to compare two independent groups.

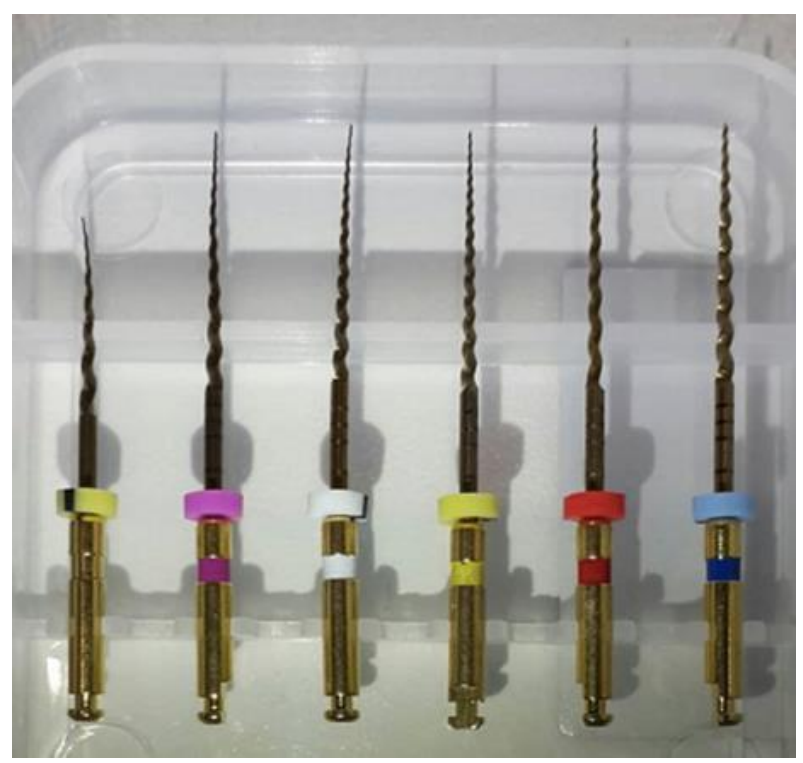

Fig. 1: A total set of V-Taper Gold Files 


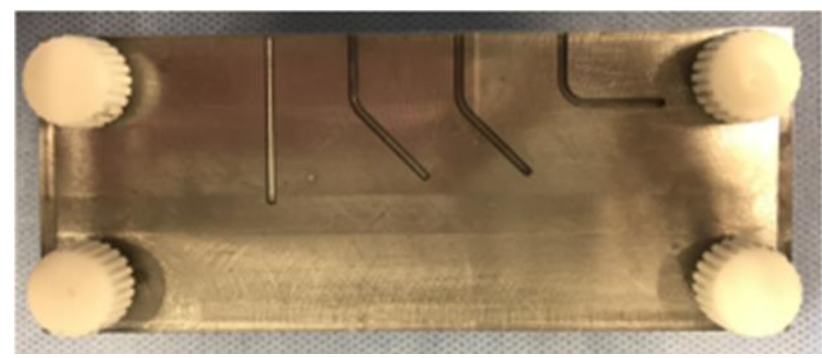

Fig. 2: The metal block with different angles that used in the study

\section{Results}

The fracture of V-Taper Gold instruments has a significantly longer cyclic fatique compared to Protaper Next instruments.

\section{Discussion}

The aim of this study is to evaluate the cyclic fatigue and the fracture resistance of engine-driven Protaper Next and V-Taper Gold instruments used in $60^{\circ}$ simulated canal.The developing new phase of alloys NiTi technology and manufacturing processes has led to a new generation of nickel titanium instruments. More flexibility ${ }^{4}$ and more resistance to cyclic fatigue 5 cause the instrument to be more durable. File fracture can usually be seen during canal instrumentation. There are multiple factors that cause file fracture, one of the main cause is the cyclic fatigue. ${ }^{6}$

Metal CNC block can not represent root dentin because of their differences in microhardness. Artificial root canal in $\mathrm{CNC}$ block has 2 dimentional curvature but natural roots may curved in 3 dimentions. Although all these limitations of this method, it provides a standart protocol in comparing the performances of different NiTi files.

The previous studies have used cylindrical metal tubes of at least $1 \mathrm{~mm}$ in diameter with differing radii and angles of curvature. Whereas others have used a sloped metal block to simulate different angles. Also the main difference of this study is to obtain realistic results the instruments were tested at a constant body temperature.

\section{Conclusion}

The Ni-Ti instruments have developing technology.This technologies decreases the risk of instrument fructure inside the root canals. The Fantadental V-Taper gold instruments have a greater cyclic fatique compared to Protaper Next rotary files.

In this study there is no human participants and animals involved. This study was not supported by any foundation.

\section{Source of funding \\ None.}

\section{Conflict of interest}

None.

\section{References}

1. Gutmann JL, Gao Y. Alteration in the inherent metallic and surface properties of nickel-titanium root canal instruments to enhance performance, durability and safety: a focused review. Int Endod J 2012;45(2):113-28.

2. Shen. Current Challenges and Concepts of the Thermomechanical Treatment of Nickel-Titanium Instrument. JOE 2013;39(2).

3. Fanta V-Taper Gold manufacturer broshure.

4. Kim. Outcome of endodontic surgery: a meta-analysis of the literature--part 1: Comparison of traditional root-end surgery and endodontic microsurgery. J Endod 2010;36(11):1757-65

5. Current Challenges and Concepts of the Thermomechanical Treatment of Nickel-Titanium Instruments. JOE 2013;39(2).

6. Pruett JP, Clement DJ, Carnes DL Jr. Cyclic fatigue testing of nickel-titanium endodontic instruments. J Endod 1997;23(2):77-85.

How to cite: Ovsay E. A comperative study of cyclic fatique resistance of two rotary systems files in artificial canals. Indian J Conserv Endod 2020;5(1):4-5. 